(2) Open Access Full Text Article

REVIEW

\title{
Laparoscopic cholecystectomy perioperative management: an update
}

This article was published in the following Dove Press journal:

Ambulatory Anesthesia

9 July 2015

Number of times this article has been viewed

\author{
Irene Sellbrant' \\ Gustaf Ledin ${ }^{2}$ \\ Jan G Jakobsson ${ }^{2}$ \\ 'Department of Anaesthesia, Capio \\ Lundby, Gothenburg, ${ }^{2}$ Department \\ of Anaesthesia and Intensive Care, \\ Institution for Clinical Science, \\ Karolinska Institutet, Danderyds \\ Hospital, Stockholm, Sweden
}

\begin{abstract}
Laparoscopic cholecystectomy is one of the most common general surgical procedures. The aim of the present paper is to review current evidence and well-established practice for elective laparoscopic perioperative management. There is no firm evidence for best anesthetic technique, further high quality studies assessing short as well as more protracted outcomes are needed. Preventive multi-modal analgesia, combining non-opioid analgesics, paracetamol, nonsteroidal anti-inflammatory drugs or coxib, and local anesthesia, has a long history. Local anesthesia improves postoperative pain and facilitates discharge on the day of surgery. Whether transversus abdominis plane-block has clinically important advantages compared to local infiltration analgesia needs further studies. Single intravenous dose steroid, dexamethasone, reduces postoperative nausea and vomiting, pain, and enhances the recovery process. Multi-modal analgesia is reassuringly safe thus having a positive benefit versus risk profile. Adherence to modern guidelines avoiding prolonged fasting and liberal intravenous fluid regime supports rapid recovery. The effects of $\mathrm{CO}_{2}$ insufflation must be acknowledged and low intra-abdominal pressure should be sought in order to reduce negative cardiovascular/respiratory effects. There is no firm evidence supporting heating and humidification of the insufflated gas. The potential risk for $\mathrm{CO}_{2} /$ gas entrainment into vasaculture, gas emboli, or subcutaneous/intra-thoracic into the pleural space must be kept in mind. Laparoscopic cholecystectomy in ASA 1-2 patients following a multi-modal enhanced recovery protocol promotes high success rate for discharge on the day of surgery.
\end{abstract}

Keywords: laparoscopic cholecystectomy, $\mathrm{CO}_{2}$ insufflation, complications, side effects, review, meta-analysis

\section{Background}

Laparoscopic cholecystectomy is one of the most common general surgical procedures. It is commonly performed as ambulatory surgery. A huge number of studies around perioperative care have been published and there are today a series of systematic reviews and/or meta-analyses describing the compiled evidence. The aim of the present update is to summarize the available best evidence and well-established practice around the perioperative care of elective laparoscopic cholecystectomy.

\section{Anesthesia}

General anesthesia is the most common anesthetic technique. Still, both spinal and epidural anesthesia may be used and have been found feasible. ${ }^{1,2}$ The need for intraoperative rescue analgesia and conversion to general anesthesia when spinal is used, in up to $8 \%$ of patients, should however be acknowledged. ${ }^{3,4}$

There are insufficient data to support any main anesthetic, intravenous (IV) or inhaled (desflurane or sevoflurane), as more effective. There are no high quality studies explicitly
Correspondence: Jan G Jakobsson Department of Anaesthesia and Intensive Care, Institution for Clinical Science, Danderyds Hospital, I82 88 Danderyd, Stockholm, Sweden

Email Jan.Jakobsson@ki.se 
assessing whether there are significant differences between the standard short-acting opioids, fentanyl, alfentanil, sufentanil, and remifentanil. The hemodynamic stress response seen associated with $\mathrm{CO}_{2}$ insufflation may be blunted by increasing depth of anesthesia, bolus dose of short-acting opioid, or the addition of preoperative clonidine (off-label use). Doses of 1 and $2 \mu \mathrm{g} / \mathrm{kg}$ clonidine have been shown safe and effective in stabilizing intraoperative hemodynamics. ${ }^{5,6}$

Intubation and muscle relaxation is still best practice although there are reports around the successful use of laryngeal mask airway, eg, the LMA ProSeal ${ }^{\circledR} .{ }^{7,8}$ There is however lack of properly powered studies around the safety associated with the use of laryngeal mask airway. The use of muscle relaxation reduces the abdominal muscle tone which facilitates visibility.

\section{Gas insufflation}

Carbon dioxide is the most commonly used gas for insufflation during laparoscopy. Nitrous oxide and helium have been studied as alternatives but their safety needs further studies. ${ }^{9}$ Low pressure carbon dioxide is preferred to abdominal wall lift and drainage does not improve postoperative pain. ${ }^{10,11}$ Intra-abdominal pressure 12 to $16 \mathrm{mmHg}$ is common practice and the lowest effective intra-abdominal pressure should be sought. Decreased pressure may however delay surgery and jeopardize safety and the benefit/risk should be assessed on an individual basis. ${ }^{12}$ There is a recent paper suggesting benefits from "deep neuromuscular block" decreasing the intra-abdominal pressure to create good visibility. ${ }^{7}$

Insufflation of gas in order to create a "gaseous cushion" for surgical visibility is of importance but causes a series of physiological effects. The venous return is decreased. A relative increase in intracranial pressure is commonly seen especially if the insufflation of gas is combined with Trendelenburg positioning. The diaphragm is shifted cranially and thus ventilation perfusion matching in the lung is impaired. Cardiac after-load is increased and subsequent cardiac output and oxygen delivery may, in patients with marginal reserve, become critically compromised. Insufflation of $\mathrm{CO}_{2}$ causes a small increase in arterial $\mathrm{CO}_{2}$ that also should be taken into account. Patients with preprocedure increased arterial carbon dioxide tension, eg, COPD, need special attention after surgery to avoid respiratory compromise. ${ }^{13}$

The risk for gas entrainment into the vasculature or surrounding tissues should also be acknowledged. ${ }^{14,15}$ Gas emboli may cause serious cardiovascular collapse. The benefits of heating and humidification of the insufflated $\mathrm{CO}_{2}$ is still debated. A meta-analysis from 2008 suggested that $\mathrm{CO}_{2}$ should, if possible, be heated and humidified for reducing pain and discomfort after surgery. ${ }^{16}$ An updated meta-analysis from 2011 could not verify any positive effects. ${ }^{17}$ There are increasing data suggesting alternatives to traditional laparoscopic technique; natural orifice transluminal endoscopic surgery (NOTES) and trans-vaginal assisted cholecystectomy have been suggested to improve postoperative recovery. ${ }^{18}$

\section{Pain management}

The concept of multi-modal analgesia, combining nonopioids aiming for additive or synergistic analgesic effect and subsequently reducing the risk for morphine-related side effects, was introduced more than 20 years ago for laparoscopic cholecystectomy by Michaloliakou et al. ${ }^{19}$ There is still strong support for the concept of multi-modal pain management facilitating intermediate recovery and discharge on the day of surgery. ${ }^{20}$ Paracetamol and nonsteroidal anti-inflammatory drugs (NSAID) as basic components and administered prior to surgery as "preventive analgesia" has become well-accepted. However a recent meta-analysis called for further high quality studies. Studies that present results from not only short/intermediate but also more protracted clinical outcomes such as time to becoming street fit, time to return to work, and quality of life. ${ }^{21}$ Intraperitoneal local anesthesia has effects reducing pain but further studies are warranted to determine more protracted outcomes. ${ }^{22,23}$ Port infiltration does reduce postoperative pain and improve recovery, eg, number of patients discharged on the day of surgery. Still further studies are warranted assessing more protracted effects. Long-acting local anesthetics are preferred. ${ }^{24}$

There is increasing interest in transversus abdominis plane block (TAP block) for pain management after abdominal surgery. There is however still insufficient data available to support routine use of TAP-block. ${ }^{25,26}$ TAP-block prior to surgery may act additive to general anesthesia and reduce anesthetic need and thus become cost effective. ${ }^{27}$ Further studies are needed in order to better define whether TAP-block would impact the recovery after laparoscopic cholecystectomy, when, and how it should be administered.

\section{Steroids - single dose IV dexamethasone}

There is reassuring support for the beneficial effects of a single preoperative IV dose of dexamethasone decreasing risk for PONV and pain. ${ }^{28,29}$ There is support for a $0.1 \mathrm{mg} / \mathrm{kg}$ dose for PONV prevention and as part of multi-modal pain management. ${ }^{30}$ There are two recent papers supporting the safety for single IV dose of dexamethasone with regard to the 
increase in blood glucose. ${ }^{31}$ The surgical stress per se does provoke an insulin resistance and raise in blood glucose and blood glucose should be managed in an adequate manner regardless of dexamethasone use..$^{32}$

\section{Analgesics for postoperative pain}

Oral regular paracetamol and NSAID in standard doses are basics. Slow-release oxycodone has been shown effective in reducing postoperative pain ${ }^{33}$ but may cause side effects if provided as premedication. Opioids may be better suited for rescue than for prevention. Pregabalin (off-label use) has been shown effective as $150 \mathrm{mg}$ preoperative without side effects while $600 \mathrm{mg}$ in two preoperative doses was found effective in reducing pain but at the cost of more dizziness. ${ }^{34,35}$ Magnesium infusion (off-label use) has been studied but the effects are limited and side effect of slower awakening has been seen. ${ }^{36,37}$ IV lidocaine (off-label use) may be as effective, $1.5-2 \mathrm{mg} / \mathrm{kg}$, followed by $2 \mathrm{mg} / \mathrm{kg} / \mathrm{h}$, which has been shown to reduce anesthetic need and postoperative pain. ${ }^{38,39}$

\section{PONV}

Female sex, age, non-smoking, prior experience of PONV (and possibly motion sickness), and need for postoperative opioids are risk factors for PONV. ${ }^{40}$ Laparoscopic cholecystectomy per se is associated with postoperative emesis. Thus, structured and proper PONV prophylaxis and management is essential. ${ }^{41}$ Avoidance of prolonged preoperative fasting and a liberal fluid regime has been shown to improve recovery avoiding nausea. Holte et al suggested a regime of $40 \mathrm{~mL} / \mathrm{kg}$ preoperatively. ${ }^{42,43}$ Whether preoperative oral carbohydrate drinks have added value requires further studies. ${ }^{44}$

\section{Summary discussion}

The literature around cholecystectomy is most extensive and the aim of this update paper is to compile and discuss preferentially meta-analyses and systematic reviews with implication for the perioperative management, benefits, and risks. There is an obvious need for further high quality prospective randomized blinded studies taking not only shortterm but more protracted outcome measures into account. There are standardized tools that could be used providing more robust evidence around short as well as more protracted multi-dimensional outcomes, eg, the Postoperative Quality of Recovery tool. ${ }^{45}$ Laparoscopic cholecystectomy is a high volume general surgery standard procedure. It is commonly done as ambulatory surgery. There is today reasonable evidence to support best practice: Multi-modal analgesia; combination of non-opioid analgesics, paracetamol and NSIADs or coxib premedication, avoidance of prolonged fasting, standard general anesthesia (there is insufficient data to support the choice of one main anesthetic propofol or inhaled agents over the other), intubation and surgical site infiltration with local anesthesia, single IV $0.1 \mathrm{mg} / \mathrm{kg}$ dose dexamethasone prior to surgery, local anesthesia intraperitoneal and in the troachar sites at end of surgery, effective evacuation of $\mathrm{CO}_{2}$ from the abdominal cavity. Use of lowest effective intra-abdominal pressure creating adequate working field should be used, awareness of the effects from capnoperitoneum and vigilant monitoring in order to maintain physiology, oxygenation, and oxygen delivery and potential gas entrainment to surrounding tissues and/or vascular space. Patients should be provided with pain medication-paracetamol, NSAID, and rescue opioid. Proper written information around postoperative pain management, convalescence, and recovery should be provided. All patients discharged on the day of surgery should be properly informed where and how to act in case of emergency.

\section{Disclosure}

Jan G Jakobsson has a consult agreement with Linde Healthcare and has received research grants from Abbott, Baxter, MSD, Nycomed, MundiPharma, and Maquet. He has also lectured and taken part in advisory boards for Baxter, Abbott, MSD, and Phizer. The authors have no other conflicts of interest to disclose in this work.

\section{References}

1. Imbelloni LE. Spinal anesthesia for laparoscopic cholecystectomy: Thoracic vs Lumbar Technique. Saudi J Anaesth. 2014;8(4):477-483.

2. Zhang HW, Chen YJ, Cao MH, Ji FT. Laparoscopic cholecystectomy under epidural anesthesia: a retrospective comparison of 100 patients. Am Surg. 2012;78(1):107-110.

3. VK, Pujari VS, RSM, Hiremath BV, Bevinaguddaiah Y. Laparoscopic Cholecystectomy Under Spinal Anaesthesia vs General Anaesthesia: A Prospective Randomised Study. J Clin Diagn Res. 2014;8(8): NC01-4.

4. Tiwari S, Chauhan A, Chaterjee P, Alam MT. Laparoscopic cholecystectomy under spinal anaesthesia: A prospective, randomised study. J Minim Access Surg. 2013;9(2):65-71.

5. Tripathi DC, Shah KS, Dubey SR, Doshi SM, Raval PV. Hemodynamic stress response during laparoscopic cholecystectomy: Effect of two different doses of intravenous clonidine premedication. JAnaesthesiol Clin Pharmacol. 2011;27(4):475-480.

6. Singh M, Choudhury A, Kaur M, Liddle D, Verghese M, Balakrishnan I. The comparative evaluation of intravenous with intramuscular clonidine for suppression of hemodynamic changes in laparoscopic cholecystectomy. Saudi J Anaesth. 2013;7(2):181-186.

7. Van Wijk RM, Watts RW, Ledowski T, Trochsler M, Moran JL, Arenas GW. Deep neuromuscular block reduces intra-abdominal pressure requirements during laparoscopic cholecystectomy: a prospective observational study. Acta Anaesthesiol Scand. 2015;59(4):434-440.

8. Beleña JM, Núñez M, Anta D, et al. Comparison of Laryngeal Mask Airway Supreme and Laryngeal Mask Airway Proseal with respect to oropharyngeal leak pressure during laparoscopic cholecystectomy: a randomised controlled trial. Eur J Anaesthesiol. 2013;30(3):119-123. 
9. Cheng Y, Lu J, Xiong X, et al. Gases for establishing pneumoperitoneum during laparoscopic abdominal surgery. Cochrane Database Syst Rev. 2013;1:CD009569.

10. Donatsky AM, Bjerrum F, Gögenur I. Surgical techniques to minimize shoulder pain after laparoscopic cholecystectomy. A systematic review. Surg Endosc. 2013;27(7):2275-2282.

11. Picchio M, Lucarelli P, Di Filippo A, De Angelis F, Stipa F, Spaziani E. Meta-analysis of drainage versus no drainage after laparoscopic cholecystectomy. JSLS. 2014;18(4).pii:e2014.00242.

12. Gurusamy KS, Vaughan J, Davidson BR. Low pressure versus standard pressure pneumoperitoneum in laparoscopic cholecystectomy. Cochrane Database Syst Rev. 2014;3:CD006930.

13. Nunes QM, Gemmill EH, Eastwood JR, Lobo DN. Carbon dioxide narcosis and grand mal seizure complicating laparoscopic herniorrhaphy. Surg Laparosc Endosc Percutan Tech. 2007;17(1):52-53.

14. Lantz PE, Smith JD. Fatal carbon dioxide embolism complicating attempted laparoscopic cholecystectomy - case report and literature review. J Forensic Sci. 1994;39(6):1468-1480.

15. Cobb WS, Fleishman HA, Kercher KW, Matthews BD, Heniford BT. Gas embolism during laparoscopic cholecystectomy. J Laparoendosc Adv Surg Tech A. 2005;15(4):387-390.

16. Sajid MS, Mallick AS, Rimpel J, Bokari SA, Cheek E, Baig MK. Effect of heated and humidified carbon dioxide on patients after laparoscopic procedures: a meta-analysis. Surg Laparosc Endosc Percutan Tech. 2008;18(6):539-546.

17. Birch DW, Manouchehri N, Shi X, Hadi G, Karmali S. Heated CO(2) with or without humidification for minimally invasive abdominal surgery. Cochrane Database Syst Rev. 2011;(1):CD007821.

18. Cheng Y, Lu J, Xiong X, et al. Gases for establishing pneumoperitoneum during laparoscopic abdominal surgery. Cochrane Database Syst Rev. 2013;1:CD009569.

19. Michaloliakou C, Chung F, Sharma S. Preoperative multimodal analgesia facilitates recovery after ambulatory laparoscopic cholecystectomy. Anesth Analg. 1996;82(1):44-51.

20. Kehlet H. Postoperative opioid sparing to hasten recovery: what are the issues? Anesthesiology. 2005;102(6):1083-1085.

21. Gurusamy KS, Vaughan J, Toon CD, Davidson BR. Pharmacological interventions for prevention or treatment of postoperative pain in people undergoing laparoscopic cholecystectomy. Cochrane Database Syst Rev. 2014;28;3:CD008261.

22. Gurusamy KS, Nagendran M, Toon CD, Guerrini GP, Zinnuroglu M, Davidson BR. Methods of intraperitoneal local anaesthetic instillation for laparoscopic cholecystectomy. Cochrane Database Syst Rev. 2014;3:CD009060.

23. Gurusamy KS, Nagendran M, Guerrini GP, Toon CD, Zinnuroglu M, Davidson BR. Intraperitoneal local anaesthetic instillation versus no intraperitoneal local anaesthetic instillation for laparoscopic cholecystectomy. Cochrane Database Syst Rev. 2014;3:CD007337.

24. Loizides S, Gurusamy KS, Nagendran M, Rossi M, Guerrini GP, Davidson BR. Wound infiltration with local anaesthetic agents for laparoscopic cholecystectomy. Cochrane Database Syst Rev. 2014;3:CD007049.

25. Charlton S, Cyna AM, Middleton P, Griffiths JD. Perioperative transversus abdominis plane (TAP) blocks for analgesia after abdominal surgery. Cochrane Database Syst Rev. 2010;(12):CD007705.

26. Johns N, O’Neill S, Ventham NT, Barron F, Brady RR, Daniel T. Clinical effectiveness of transversus abdominis plane (TAP) block in abdominal surgery: a systematic review and meta-analysis. Colorectal Dis. 2012;14(10):e635-e642.

27. Kokulu S, Bakı ED, Kaçar E, et al. Effect of transversus abdominis plane block on cost of laparoscopic cholecystectomy anesthesia. Med Sci Monit. 2014;20:2783-2787.

28. Karanicolas PJ, Smith SE, Kanbur B, Davies E, Guyatt GH. The impact of prophylactic dexamethasone on nausea and vomiting after laparoscopic cholecystectomy: a systematic review and meta-analysis. Ann Surg. 2008;248(5):751-762.
29. Si XY, Wu LP, Li XD, Li B, Zhou YM. Dexamethasone combined with other antiemetics for prophylaxis after laparoscopic cholecystectomy. Asian J Surg. 2015;38(1):21-27.

30. De Oliveira GS Jr, Almeida MD, Benzon HT, McCarthy RJ. Perioperative single dose systemic dexamethasone for postoperative pain: a meta-analysis of randomized controlled trials. Anesthesiology. 2011;115(3):575-588.

31. Murphy GS, Szokol JW, Avram MJ, et al. The effect of single low-dose dexamethasone on blood glucose concentrations in the perioperative period: a randomized, placebo-controlled investigation in gynecologic surgical patients. Anesth Analg. 2014;118(6):1204-1212.

32. Abdelmalak BB, Bonilla AM, Yang D, et al. The hyperglycemic response to major noncardiac surgery and the added effect of steroid administration in patients with and without diabetes. Anesth Analg. 2013;116(5):1116-1122.

33. Fanelli G, Ghisi D, Berti M, et al. Preoperative administration of controlled-release oxycodone as a transition opioid for total intravenous anaesthesia in pain control after laparoscopic cholecystectomy. Surg Endosc. 2008;22(10):2220-2228.

34. Bekawi MS, El Wakeel LM, Al Taher WM, Mageed WM. Clinical study evaluating pregabalin efficacy and tolerability for pain management in patients undergoing laparoscopic cholecystectomy. Clin J Pain. 2014;30(11):944-952.

35. Sarakatsianou C, Theodorou E, Georgopoulou S, Stamatiou G, Tzovaras G. Effect of pre-emptive pregabalin on pain intensity and postoperative morphine consumption after laparoscopic cholecystectomy. Surg Endosc. 2013;27(7):2504-2511.

36. Kocman IB, Krobot R, Premuzić J, et al. The effect of preemptive intravenous low-dose magnesium sulfate on early postoperative pain after laparoscopic cholecystectomy. Acta Clin Croat. 2013;52(3): 289-294.

37. Olgun B, Oğuz G, Kaya M, et al. The effects of magnesium sulphate on desflurane requirement, early recovery and postoperative analgesia in laparascopic cholecystectomy. Magnes Res. 2012;25(2):72-78.

38. Saadawy IM, Kaki AM, Abd El Latif AA, Abd-Elmaksoud AM, Tolba OM. Lidocaine vs magnesium: effect on analgesia after a laparoscopic cholecystectomy. Acta Anaesthesiol Scand. 2010;54(5): 549-556.

39. Lauwick S, Kim do J, Michelagnoli G, et al. Intraoperative infusion of lidocaine reduces postoperative fentanyl requirements in patients undergoing laparoscopic cholecystectomy. Can J Anaesth. 2008; 55(11):754-760.

40. Öbrink E, Jildenstål P, Oddby E, Jakobsson JG. Post-operative nausea and vomiting: Update on predicting the probability and ways to minimize its occurrence, with focus on ambulatory surgery. Int J Surg. 2015;15:100-106.

41. Kranke P, Diemunsch P. The 2014 consensus guidelines for the management of postoperative nausea and vomiting: a leapfrog towards a postoperative nausea and vomiting-free hospital. Eur J Anaesthesiol. 2014;31(12):651-653.

42. Zelić M, Štimac D, Mendrila D, et al. Preoperative oral feeding reduces stress response after laparoscopic cholecystectomy. Hepatogastroenterology. 2013;60(127):1602-1606

43. Holte K, Klarskov B, Christensen DS, et al. Liberal versus restrictive fluid administration to improve recovery after laparoscopic cholecystectomy: a randomized, double-blind study. Ann Surg. 2004; 240(5):892-899.

44. Singh BN, Dahiya D, Bagaria D, et al. Effects of preoperative carbohydrates drinks on immediate postoperative outcome after day care laparoscopic cholecystectomy. Surg Endosc. Epub January 22, 2015.

45. Bowyer A, Jakobsson J, Ljungqvist O, Royse C. A review of the scope and measurement of postoperative quality of recovery. Anaesthesia. 2014;69(11):1266-1278 


\section{Publish your work in this journal}

Ambulatory Anesthesia is an international, peer reviewed, open access journal publishing articles that address all aspects of ambulatory anesthesia practice, in particular: anesthetic techniques, sedation and safety practices, pharmacokinetics, preoperative evaluation, analgesia interventions, regulatory and compliance issues, postoperative recovery,

Submit your manuscript here: http://www.dovepress.com/ambulatory-anesthesia-journal
Dovepress

patient satisfaction, administrative topics, and cost analysis themes. The manuscript management system is completely online and includes a very quick and fair peer review system, which is all easy to use. Visit $\mathrm{http}: / /$ www.dovepress.com/testimonials.php to read real quotes from published authors. 